\title{
RELAÇÃO CálCIO/PROTÉ́NA DA DIETA DE MULHERES NO CLIMATÉRIO
}

\author{
Regina das Neves Girão Montilla*, José Mendes Aldrighi, Maria de Fátima Nunes Marucci \\ Trabalho realizado no Centro de Saúde-Escola Geraldo de Paula Souza \\ da Faculdade de Saúde Pública da Universidade de São Paulo, São Paulo, SP.
}

\begin{abstract}
RESUMO - Objetivo. Avaliar a relação cálcio/proteína da dieta de mulheres no climatério.

Métodos. Em estudo transversal, foi avaliada a dieta de 154 mulheres entre 35 e 65 anos de idade, atendidas no Ambulatório de Saúde da Mulher Climatérica do Centro de Saúde-Escola da Faculdade de Saúde Pública da Universidade de São Paulo. Para obtenção do consumo alimentar de cálcio e de proteína, foi realizado inquérito alimentar pelo método "recordatório de 24 horas". A avaliação da relação cálcio/proteína foi feita segundo proposta de Massey e Heaney (1998), que é de $20 / \mathrm{l}(\mathrm{mg} / \mathrm{g})$.
\end{abstract}

Resultados. 0 consumo médio de cálcio foi de $624,9 \mathrm{mg}$ o de proteínas foi $86,7 \mathrm{~g}$ e a relação cálcio/proteína foi de $7 / 1$ $(624,9 \mathrm{mg} / 86,7 \mathrm{~g})$.

ConcLUsÃo. A população estudada apresenta consumo inadequado dos nutrientes cálcio e proteína, podendo resultar em sérios riscos à saúde.

Unitermos: Relação cálcio/proteína. Consumo alimentar. Menopausa. Osteoporose.

\section{INTRODUÇÃO}

Evidências indicam que muitas doenças crônicas resultam da interação de fatores genéticos, ambientais e estilo de vida e, neste último, destaca-se a dieta como a maior responsável'.

Sabe-se também que entre as principais morbidades que acometem a mulher no climatério inclui-se a osteoporose ${ }^{2,3}$, doença de grande impacto tanto na saúde pública como socioeconômico, em função de seus altos custos diretos e indiretos ${ }^{4}$. Além disso, com o aumento da expectativa de vida, cresce também o número de idosos e de fraturas osteoporóticas, particularmente em mulheres ${ }^{5}$. Segundo dados recentes, no grupo etário de 50 anos, verificam-se cinco mulheres acometidas por osteoporose para cada homem $^{4}$. Estas são especialmente vulneráveis, em decorrência da progressiva redução da função ovariana e, conseqüentemente, da produção de seus hormônios esteróides ${ }^{6,7}$. Este processo inicia-se a partir dos 35 anos, quando a mulher apresenta redução lenta de massa óssea, acentuando-se após os 50 anos, momento em que comumente ocorre a menopausa ${ }^{8}$.

Outro fator que pode tornar-se prejudicial à saúde óssea é o consumo dietético inadequado de cálcio, pois uma das principais deficiências nutricionais no climatério refere-se a

*Correspondência:

regina.montilla@uol.com.br este nutriente. Este fato compromete a mineralização e a manutenção óssea, promovendo, dessa forma, o agravamento da osteoporose, ${ }^{9,10}$. De fato, alguns estudos sobre consumo alimen$\operatorname{tar}^{11,12,13}$ mostram que dos nutrientes avaliados, o cálcio é o que apresenta maior inadequação.

Além disso, vários estudos indicam que o consumo excessivo de proteína pode ter efeito deletério, seja por estimular as perdas excessivas de cálcio ou por acelerar a diminuição da função renal vinculada à idade 2,10,14-17. Este fato deve ser levado em consideração devido à redução progressiva de massa óssea, principalmente em mulheres pós-menopausais $^{10}$. Em estudo envolvendo mulheres e homens idosos, Meyer et al. ${ }^{18}$ identificaram significante associação positiva de consumo de proteína com risco de fratura de quadril e ingestão de cálcio menor que 400 mg/dia, em ambos os sexos. Segundo Dawson-Hughes \& Harris $^{19}$, a ingestão de cálcio parece influenciar a associação de proteína ingerida com a absorção de cálcio, pois em estudo realizado também com mulheres e homens idosos, verificou-se que consumo inferior a $800 \mathrm{mg} /$ dia de cálcio e alta ingestão protéica ( 17\% do total energético) foi associado com redução de $23 \%$ da absorção de cálcio, enquanto que maior consumo deste nutriente aumentou sua absorção, sem mudança significativa com aumento na ingestão de proteína.

Portanto, uma dieta com baixa ingestão de cálcio e excessivo consumo protéico poderia comprometer ainda mais a osteoporose, que é um dos problemas de saúde pública mais prevalentes, principalmente em mulheres pós-menopausais ${ }^{20}$. Com o propósito de evitar este tipo de problema e, conseqüentemente proteger os ossos, alguns autores ${ }^{16,17}$ preconizam que a relação cálcio/proteína da dieta seja de 20/I (mg/g). Por isso, o objetivo deste estudo foi avaliar a relação cálcio/proteína, a partir do consumo desses nutrientes na dieta de mulheres no climatério, atendidas em Centro de Saúde-Escola.

\section{Métodos}

Trata-se de estudo transversal com coleta de dados primários, realizado no Ambulatório de Saúde da Mulher Climatérica (ASMUC) do Centro de Saúde-Escola Geraldo de Paula Souza da Faculdade de Saúde Pública da Universidade de São Paulo. As mulheres matriculadas no ASMUC eram encaminhadas primeiramente à consulta médica, sendo solicitados os exames necessários (dosagem hormonal, colesterol, triglicérides, glicemia, mamografia, densitometria óssea, etc). Após atendimento médico, as pacientes eram convidadas a participar deste estudo e, em caso afirmativo, assinavam o termo de consentimento. Verificou-se o consumo alimentar de cálcio e proteína de 154 mulheres por meio de inquérito alimentar através do método "recordatório de 24 horas", considerado um bom instrumento para grupos populacionais" ${ }^{21}$. 
Este método consiste na definição e quantificação das preparações e/ou alimentos ingeridos durante o dia anterior à entrevista. Esta quantificação foi feita sob forma de medidas caseiras, avaliando-se o consumo alimentar no tocante à proteína e ao cálcio. As quantidades dos alimentos foram processadas pelo "software" Virtual Nutri22, que calcula o total de nutrientes dos alimentos consumidos. Para avaliação da relação cálcio/proteína, utilizouse como parâmetro a relação sugerida por Massey $^{16}$ e Heaney $^{17}$, que é de 20/l (20 mg de cálcio para cada grama de proteína). As médias foram calculadas pelo aplicativo Excel $2000 \mathrm{da}$ Microsoft@.

\section{Resultados}

Para o cálcio dietético, a média de consumo foi $624 \mathrm{mg}$. Em relação às proteínas, o consumo médio foi 87 g. Ao avaliar a relação cálcio/proteína, constatou-se o seguinte resultado: $7 / /(624 \mathrm{mg} / 87 \mathrm{~g})$.

\section{Discussão}

Apesar da existência de alguns estudos que mostram a importância do aumento da recomendação do cálcio para a mulher climatérica ${ }^{10,23}$, o resultado do presente estudo indicou baixo consumo deste nutriente $(624 \mathrm{mg})$. Esse resultado foi inferior ao obtido por Galeazzi et al. "', que verificaram o consumo alimentar em cinco municípios brasileiros (Rio de Janeiro, Campinas, Curitiba, Goiânia e Ouro Preto). Nesse estudo, o consumo médio de cálcio (em mulheres com idade de 45-65 anos), nas cinco cidades brasileiras, foi de $917 \mathrm{mg}$ de cálcio. Outros estudos nacionais, apesar de envolverem idosos (homens e mulheres), também apresentaram consumo inadequado de cálcio ${ }^{13,24-26}$. É importante, no entanto, considerar que, o êxito do tratamento de indivíduos com osteoporose é consideravelmente menor do que a prevenção desta 27 ; por isso, uma dieta adequada em cálcio na infância e adolescência aumentaria o pico de massa óssea, reduzindo assim o risco de osteoporose décadas mais tarde ${ }^{28}$. Para reforçar ainda mais a importância do consumo adequado de cálcio na prevenção da osteoporose, Yates et al. ${ }^{23}$ admitem que 0 incremento da ingestão do cálcio na dieta (I000-I200 mg), mesmo em mulheres pós-menopausais, retardaria eventuais perdas de cálcio ósseo. Contudo, Hegsted ${ }^{29}$ considera que existem poucas evidências sobre $\mathrm{o}$ alto consumo deste nutriente e a efetiva prevenção de fraturas. Além disso, este autor afirma ainda que as recomendações de cálcio são tão altas atualmente, que é difícil atingi-las sem mudanças nos hábitos alimentares. De fato, os resultados deste e outros estudos $11,12,13,24-26$ mostraram que o consumo de cálcio apresentouse muito abaixo dos padrões recomendados.

Quanto às proteínas, os resultados revelaram elevado consumo de proteína $(86,7 \mathrm{~g})$, lembrando que, de acordo com o National Research Counci ${ }^{30}$, a recomendação deste nutriente é de $0,8 \mathrm{~g} / \mathrm{kg}$ de peso. Este resultado sugere a preferência da população por alimentos protéicos. Vários estudos sobre consumo alimentar confirmam essa tendência de alto consumo de proteínas na dietal $11,12,13,24-26$. Esse excesso protéico deve servir de alerta, pois inúmeros estudos mostram que a ingestão exagerada de proteína pode propiciar perdas excessivas de cálcio 2,10,15-17,32,33. Contudo, no estudo de Dawson Hughes \& Harris ${ }^{19}$, avaliando dois grupos, um tratado com placebo e outro com suplementação de cálcio e associando ingestão protéica com densidade mineral óssea, encontraram resultados diferentes. O grupo suplementado foi positivamente associado com ganho ósseo, enquanto que no grupo não suplementado houve perda de massa óssea. Aqueles com alta ingestão protéica ganharam massa óssea, enquanto que aqueles com baixa ingestão perderam massa óssea. O cálcio não foi suficiente $(87 \mathrm{lmg})$ para proteger o esqueleto quando a ingestão protéica era baixa, porém a alta ingestão de proteína não afetou o estado ósseo.

De acordo com Heaney ${ }^{34}$, o efeito positivo da proteína está relacionado à constituição óssea, ou seja, $50 \%$ do osso é formado por colágeno e a outra metade por cálcio ${ }^{29}$. Os aminoácidos do colágeno não são reutilizados em nova síntese protéica e quando a proteína dietética é insuficiente, a reconstrução tornase prejudicada devido a outras prioridades funcionais deste nutriente. Portanto, em dieta com consumo inadequado de cálcio e de proteína, a reconstrução óssea estaria limitada. Assim, tem sido especulado que, aparentemente, o efeito paradoxo da proteína no osso pode ser explicado pelas variações na ingestão do cálcio $^{34}$. Segundo Heaney ${ }^{35}$, a proteína e o cálcio atuariam sinergicamente no osso, se ambos apresentarem quantidades adequadas na dieta, porém, a proteína pode parecer efetivamente antagonista para o osso quando a ingestão de cálcio for baixa.

Neste estudo, notou-se consumo dietético inadequado em ambos os nutrientes, sendo alto para proteína e baixo para cálcio, e, conseqüentemente, a relação cálcio/proteína também apresentou-se inadequada.

Por isso, é fundamental que estes achados sejam lembrados, principalmente em mulheres após a menopausa, onde se constata nítida e progressiva perda de massa óssea ${ }^{10}$.

Em termos práticos, a proposta deste estudo, numa eventual orientação nutricional, seria inicialmente adequar o consumo do cálcio, que comumente é o nutriente mais deficiente e tem recomendação aumentada durante o climatério; somente após a adequação do cálcio, objetivar-se-ia adequar o da proteína. Portanto, na relação cálcio/proteína de 20:I (mg/g) parece ser mais coerente estimular dieteticamente o consumo de cálcio e, a partir deste, adequar a quantidade de proteína da dieta, a fim de proteger o sistema ósseo contra a osteoporose que, sem dúvida, representa uma das afecções que propicia grande impacto socioeconômico e na saúde pública.

\section{SUMMARY \\ Calcium/protein relation of women ON THE CLIMACTERIC}

OBJETIVE. To evaluate the calcium/protein relation of the diet of climacteric women. METHODS. In a transversal study the diet was evaluated of 154 women 35-65 years old and matriculated in the Health Clinic of the Climateric Woman of Health Center of Public Health College of the São Paulo University. The food intake of calcium and protein was food investigated by "24 hours recall" method. The evaluation of calcium/protein relation was made according to Massey and Heaney (1998), that is $20 / 1$ (mg/g).

REsULTS. The mean of intake of calcium was $624.9 \mathrm{mg}$; the mean of intake of protein was $86.7 \mathrm{~g}$ and the calcium/protein relation was $7 / 1$ (624.9 mg/86.7 g).

ConcLusion. The studied population presents inadequated consumation of the calcium and protein nutrients. It could result in serious risk for health. [Rev Assoc Med Bras 2004; 50(I): 52-4]

KEY wORDS. Calcium/protein relation. Food intake. Menopause. Osteoporosis. 


\section{REFERÊNCIAS}

I. Wynder E, Andres R. Workshop A: diet and nutrition research as it relates to aging and chronic diseases. Prev Med 1994; 23:549-5I.

2. [OMS] Organización Mundial de la Salud. Dieta, nutrición y prevención de enfermidades crónicasn. Ginebra; 1990. (Série de Informes Técnicos, 797).

3. Sutnick M. Nutritional aspects of the menopause. In: Eskin BA. The menopause: comprehensive management. 3th ed. New York: MacGraw Hill; 1994. p. I55-70.

4. Marques Neto JF. Campanha Nacional de Prevenção da Osteoporose. São Paulo: Merck Sharp \& Dohme, BG Cultural; 200 I. p. I 5-52.

5. [OHE] Office Health Economics. Osteoporose e o risco de fratura. Tradução na íntegra de: Office Health Economics. Copyright cedido por OHE. 12 Whitehall London SWI A 2DY; 1990. p.3-40.

6. Halbe HW. Filosofia do atendimento da mulher menopausal. In: Pinotti JA et al. Menopausa. São Paulo: Roca; 1995. p.221-6.

7. Aldrighi JM. Balanço risco/benefício da terapêutica da reposição hormonal: direções para o futuro. Rev Soc Cardiol Estado de São Paulo 1996; 6:734-8.

8. [OMS] Organización Mundial de la Salud. Investigaciones sobre la menopausia en los años novientan. Ginebra; 1996. (Série de Informes Técnicos, 866).

9. Stevenson JC. Determinants of bone density in normal women: risk factors for future osteoporosis? Br Med J 1989; 298:924-8.

I0. Johnston CC Jr. Osteoporosis. In: Eskin BA. The menopause: comprehensive management. 3th ed. New York: MacGraw Hill; 1994. p. $103-17$

1।. Galeazzi MAM, Domene SMA, Sichiere R. Estudo multicêntrico sobre consumo alimentar. Cadernos de debate - Revista do Núcleo de Estudos e Pesquisas em alimentação/ UNICAMP. Ministério da Saúde; 1997. Volume especial.
12. Montilla RNG, Marucci MFN, Aldrighi JM. Avaliação do estado nutricional e do consumo alimentar de mulheres no climatério. Rev Assoc Med Bras 2003; 49:91-5.

13. Sampaio LR. Avaliação da dieta de idosos residentes no município de São Paulo (dissertação). São Paulo: FEA/FCF/FSP da Universidade de São Paulo; 1997.

14. Heaney RP, Gallagher JC, Johnston CC, Neer R, Parfitt AM, Chir B et al. Calcium nutrition and bone health in the elderly. Am J Clin Nutr 1982; 36:986-13.

15. Barzel US, Massey LK. Excess dietary protein can adversely affect bone. J Nutr 1998; 128:1051-3.

16. Massey LK. Does excess dietary protein adversely affect bone? J Nutr 1998; 128: 1 048-50.

17. Heaney RP. Excess dietary protein may not adversely affect bone. I Nutr 1998; 128: 1054-7.

18. Meyer HE, Pederson JI, Loken EB, Tverdal A. Dietary factors and the incidence of hip fracture in middle aged Norwegians. Am J Epidemiol 1997; | 45: | |7-23.

19. Dawson-Hughes B, Harris SS. Calcium intake influences the association of protein intake with rates of bone loss in elderly men and women. Am J Clin Nutr 2002; 75:773-9.

20. Sakamoto LC, Halbe HW. Epidemiologia da menopausa. In: Pinotti JÁ et al. Menopausa. São Paulo: Roca; 1995. p. I-9.

21. Krause MV, Mahan LK. Avaliação do estado nutricional. In: Krause MV, Mahan LK Alimentos, nutrição e dietoterapia. 7a ed. São Paulo: Roca; 1991. p.192-14

22. Philippi ST, Szarfarc SC, Latterza AR. Virtual Nutri ("software"), versão 1.0 for Windows. São Paulo: Departamento de Nutrição da Faculdade de Saúde Pública, Universidade de São Paulo; 1996.

23. Yates AA, Schlincker SA, Suitor CW. Dietary reference intakes: the new basis for recommendation for calcium and related nutrients $B$ vitamins, and choline. J Am Diet Assoc 1998; 98:688-706.
24. Novaes VLSS. Padrão dietético de idosos de 80 anos e mais, atendidos em ambulatório de geriatria na capital de São Paulo (dissertação). São Paulo; FEA/FCF/FSP da Universidade de São Paulo; 1997.

25. Marucci MFN. Avaliação das dietas oferecidas em instituições para idosos, localizadas no município de São Paulo (dissertação). São Paulo; Universidade de São Paulo; 1985.

26. Menezes TN. Avaliação antropométrica e do consumo alimentar de idosos residentes em instituições geriátricas da cidade de Fortaleza, Ceará. 2000 [Dissertação de mestrado Universidade de São Paulo]

27. Kanis JÁ. Treatment of osteoporotic fracture. Lancet 1984; 1:27-33.

28. Hathcock JN. Vitamins and minerals: efficacy and safety. Am J Clin Nutr 1997; 66:427-37.

29. Hegsted DM. Fractures, calcium, and the modern diet. Am I Clin Nutr 200 I; 74:57 I-3.

30. National Research Council (US). Subcomittee on the tenth edition of the RDAs. Recommended dietary alowances $10^{\text {th }}$ ed. Washington: National Academy Press; 1989.

31. Mondini L, Monteiro CA. Mudanças no padrão de alimentação da população urbana brasileira (1962-1 988). Rev Saúde Pública 1994; 28:433-9.

32. Nagant De Deuxchaisnes C. Nutritional factor in osteoporosis. In: Notelovitz M, VanKeep P. The climateric in perspective. London: MTP Press Limited; 1986. p.355-9.

33. Sellmeyer DL, Stone KL, Sebastian A, Cummings SR. A high ratio of dietary animal to vegetable protein increases the rate of bone loss and the risk of fracture in postmenopausal women. Am J Clin Nutr 200 I; 73: I I 8-22.

34. Heaney RP. Calcium, products and osteoporosis. J Am Coll Nutr 2000; 19:(suppl):83S-99S.

35. Heaney RP. Protein and calcium: antagonists or synergists? Am J Clin Nutr 2002; 75:609- I 0.

Artigo recebido: 29/1 I/02

Aceito para publicação: 06/10/03 